\title{
WAGE DIFFERENTIALS ACROSS FIRMS: AN APPLICATION OF MULTILEVEL MODELLING
}

\author{
A. R. CARDOSO* \\ Minho University, Braga, Portugal, NIMA and CEPR
}

\begin{abstract}
SUMMARY
Multilevel modelling techniques are applied to a dataset that matches firms and workers, to pinpoint and explain contrasts among company wage policies. Results indicate that wage differences across firms are statistically significant, affecting every parameter of the pay policy (returns to schooling, tenure, experience, the penalty imposed on newly hired workers and on women). Gross labour productivity, average schooling in the firm, firm size and economic sector are relevant forces shaping the contrast between employers' pay policies. Copyright (C) 2000 John Wiley \& Sons, Ltd.
\end{abstract}

\section{INTRODUCTION}

Early research on wage differentials has highlighted the relevance of wage policies at firm level. ${ }^{1}$ More recently, however, the topic has been subject to debate. In particular, Groshen (1991) stressed the relevance of employer wage effects in shaping overall labour market inequality, while Leonard (1989), using similar econometric methodologies applied to the same country (the USA), argued instead that firm wage effects play a negligible role in explaining wage variation. The topic therefore deserves further scrutiny.

This study aims, first, to identify contrasts among company wage policies, testing the hypothesis that different firms reward differently the human capital of their workers. It then progresses to the explanation of the differences in the behaviour of firms. The following questions will be asked: What parameters of the pay policy - returns to schooling, tenure, experience, penalty imposed on women and on newly hired workers - differ across firms? For what kind of workers are the wage contrasts among firms more pronounced? What employer attributes are more relevant in determining contrasts among company wage policies?

Portugal is one of the OECD economies with the highest degrees of wage flexibility and the responsiveness of wages to the macro unemployment rate has been extensively documented (see OECD, 1992, or Modesto and Monteiro, 1993). Are firms free to adjust wages according to the conditions prevailing at the micro level as well? The intermediate nature of centralization in the Portuguese wage bargaining system allows no clear-cut a-priori answer. The fact that guidelines for wage increases are set each year at the national level by the government, employers'

\footnotetext{
* Correspondence to: A. R. Cardoso, Department of Economics, Minho University, Gualtar, 4700 Braga, Portugal; e-mail: cardoso@eeg.uminho.pt

Contract/grant sponsor: Ministério dos Negócios Estrangeiros, Portugal.

${ }^{1}$ See the overview by Kerr (1994) or the original papers by Lester (1948), Lester (1952), Dunlop (1957) and Reynolds (1951), who relied on extensive fieldwork of American companies or, setting a novel framework that has influenced much of the current work in this area, Rees and Shultz (1970), who used an econometric analysis of micro data on workers.
} 
federations and trade unions' associations, points towards some centralization in the system. Also, the impact of union action goes beyond union membership, as there are widespread extension mechanisms at work, in particular once employers apply an agreement signed with a trade union to all of their workforce, irrespective of the worker's union membership status. On the other hand, some decentralization is provided by the scattered nature of the union structure, and by the possibility of bargaining at the firm level. Moreover, wage drift has been steadily increasing in the Portuguese economy, allowing employers to adjust their wage policy to the firm's conditions.

From a methodological point of view, 'employer wage effects' have almost invariably been evaluated as the coefficients of employer dummy variables, in a wage regression where controls for worker characteristics have been introduced (see for example the papers by Groshen, 1991; Leonard, 1989; Lucifora, 1993; or Knight and Sabot, 1983). This study aims at going beyond the traditional approach of reducing firm wage effects to an employerspecific intercept in the wage regression. That approach provides one unambiguous measure of the firm wage effect, which can be regressed on the firm attributes to explain why some firms pay better than others. As such, it has yielded interesting insights into employers pay policies and has facilitated the analysis of its causes. However, it is too restrictive, as it disregards that different firms may value the human capital attributes of their workers differently. That is more so, the further the labour market is from a perfectly competitive mechanism. Furthermore, a particular assumption concerning the mechanism of wage bargaining within the firm is implicit. It presumes that firm-wide trade unions bargain for every worker in the firm, extracting in the end a uniform reward, beyond the returns on the worker's human capital, which holds for every worker in the company. A different mechanism is instead likely to operate in most countries, and in particular in Portugal, where negotiation is often fragmented, especially in the services sector where occupation-based unions predominate. Workers with different characteristics are thus likely to be able to gain different shares of the economic rents to be divided.

Therefore, employers' wage policies will be modelled as employer-specific intercepts and slopes in the wage regression, and tests on the equality of parameters across firms will be performed. Some progress in this direction had been made by Kramarz et al. (1996) when estimating a separate wage regression for each firm. However, the model to be used should not just allow for the estimation of firm-specific coefficients, enabling the identification of contracts among company wage policies. A more demanding objective would be to explain that multidimensional set of employer wage effects, detecting the sources of wage variability across firms. Moreover, both steps of the estimation process should ideally be joined, in one estimation framework. Multilevel modelling will be used. This type of model provides, furthermore, a more adequate description of the mechanisms actually taking place in the labour market, an issue that will deserve further comment in the next section.

The multilevel model to be used is described in Section 2. Section 3 concentrates on the dispersion of wage parameters across firms. Sections 4 and 5 both search for the causes of contrasts among company wage policies. In Section 4, the variability in the wage parameters across firms is modelled as a function of the firm characteristics, therefore identifying systematic components in company wage policies. In Section 5, the random wage variation across employers is modelled as a function of worker attributes. Section 6 presents conclusions. 


\section{ECONOMETRIC PROCEDURE TO ESTIMATE EMPLOYER-SPECIFIC EFFECTS IN A WAGE REGRESSION}

A particularly appropriate dataset for the study of company wage policies is available for Portugal, gathered by the Ministry of Employment and Social Security. It matches employers and employees, and reported data include the worker's gender, age, skill, occupation, schooling, tenure, earnings, as well as the firm's location, industry, employment level, sales volume and legal setting. ${ }^{2}$

Hierarchical or multilevel models explicitly handle situations where the group-varying parameters estimated in one level are treated as the dependent variables in the next level equations. The multidimensional set of estimated firm-specific wage parameters are modelled as random effects with systematic components, thus joining both steps of the estimation process.

The foundations for linear hierarchical models or multilevel models have been laid down by Lindley and Smith (1972), who proposed a Bayes estimator for hierarchical data models with complex error structures, highlighting its low dispersion, reflected in a low mean squared error. This modelling approach has been advocated in particular by Haitovsky (1986), responsible for the development to $k$-level hierarchical models.

Consider two different levels making up the particular model of this study. In the first level, the unit of observation is the worker:

$$
y_{i j}=X_{i j}^{\prime} \beta_{j}+e_{i j}
$$

with the subscript $i$ referring to the worker, $j$ to his/her firm; $y$ is the log of hourly earnings; $X$ includes $K$ regressors (the worker attributes and the constant term), and $e_{j} \approx N\left(0, \sigma_{j}^{2}\right)$.

The level- 2 model explains the $\beta_{j}$ coefficients estimated in the first level, based on $l$ firm-level variables:

$$
\beta_{j}=G_{j} \eta+\alpha_{j}
$$

where $j$ keeps its meaning, referring to the firm; $G_{j}=I_{K} \otimes g_{j}$ and $g_{j}$ is an $(l \times 1)$ matrix of firm attributes; $\eta$ is a $(k l \times 1)$ matrix with the coefficients of the impact of the firm attributes on each of its pay parameters; $\alpha_{j} \approx N(0, \Gamma), \Gamma$ being a $K \times K$ matrix; $\alpha_{j}$ is independent of $e_{j}$. $\beta_{j}$ is thus made up of a systematic/fixed component $\left(G_{j} \cdot \eta\right)$ and a random component $\left(\alpha_{j}\right)$. Note in particular that the fixed component depends on the firm attributes.

Merging models (1) and (2) yields:

$$
y_{i j}=X_{i j}^{\prime} \cdot G_{j} \cdot \eta+X_{i j}^{\prime} \cdot \alpha_{j}+e_{i j}
$$

The fixed part of the model, given by the first term on the right-hand side of equation (3), describes the average wage in the economy, given attributes $X_{i j}$ and $G_{j}$. The coefficients $\alpha_{j}$ describe employer deviations from the economy's standard, and $e_{i j}$ captures worker deviations from his or her employer average wage. The random part, split into two components, embodies particular characteristics of this type of model. In fact, the presence of more than one residual term is a characteristic of multilevel models, and in this case two levels - the worker and the firm - of random variation are allowed for. Moreover, the variance of the error terms can itself be

\footnotetext{
${ }^{2}$ See the Appendix for descriptive statistics. Detailed information on the dataset can be obtained from the author.
} 
modelled. In particular the error term can be heteroscedastic, and correlation within the firm is allowed for, as opposed to traditional OLS estimation where one single random term is considered, assumed usually to have constant variance.

If the firm-specific parameters $\beta_{j}$ did not depend on the firm attributes, then they would be drawn from a distribution with mean $\beta$, and the level-2 model in equation (2) would simplify to:

$$
\beta_{j}=\bar{\beta}+\alpha_{j}
$$

Equation (3) would in that case become

$$
y_{i j}=X_{i j}^{\prime} \cdot \bar{\beta}+X_{i j}^{\prime} \cdot \alpha_{j}+e_{i j}
$$

\section{THE DISPERSION OF WAGE PARAMETERS ACROSS FIRMS}

Consider equation (3'). A general to specific modelling approach was followed in the estimation of the model. ${ }^{3}$ Successive testing led to the selection of the variables kept in the fixed part of the model, and of the elements in the covariance matrix $\Gamma$. Variables were dropped from the general model, one at a time, before progressing to the next round of testing. To check the significance of the variance and covariance terms, a $t$-statistic test is known to be inadequate, as its distributional assumptions are less likely to be met. Instead, the likelihood-ratio test is the proper procedure (see for instance Woodhouse et al., 1996, p. 32 or Longford, 1993, p. 26, 35). Such testing has been performed, at the $1 \%$ significance level. The specific model reached is reported in Table I.

To clarify the interpretation of the results, let us keep in mind that the estimation process provides estimates for:

- The fixed parameters, $\beta$ : the average estimated value in the economy for the pay parameters. These coefficients are reported in the first panel of Table I.

- The random parameters: estimates of the elements of the matrix $\Gamma$ (a $K \times K$ matrix). The elements of the matrix provide the variances and covariances of the pay parameters, reported in the second panel of the table.

The average rate of return to one extra year of schooling is $6 \cdot 1 \%$, a value in line with previous estimates of wage regressions, in particular for the Portuguese case (see, for example, Vieira et al., 1997). A point to be noted is the fact that, while an additional year of seniority with the firm leads to a wage raise of $0.6 \%$, newcomers to the firm (less than a year of seniority) are subject to a wage penalty of $5 \cdot 2 \%$. Testing by Vieira et al. (1997) had also pointed to the linearity of the tenure profile, after accounting for the wage differential during the first year with the firm. This finding may reflect the situation of workers on short-term contracts, whose duration is most often set at six months. An extra year of labour market

\footnotetext{
${ }^{3}$ Generalized least squares estimation has been performed. The Iterative Generalized Least Squares procedure is described in detail in Goldstein (1986), and a synthesis is provided in Goldstein (1995, pp. 21-23, 38-40). The continuous variables were evaluated as deviations from their overall means, so that the intercept is evaluated at a point that does not fall outside the range of the explanatory variables.
} 
WAGE DIFFERENTIALS ACROSS FIRMS

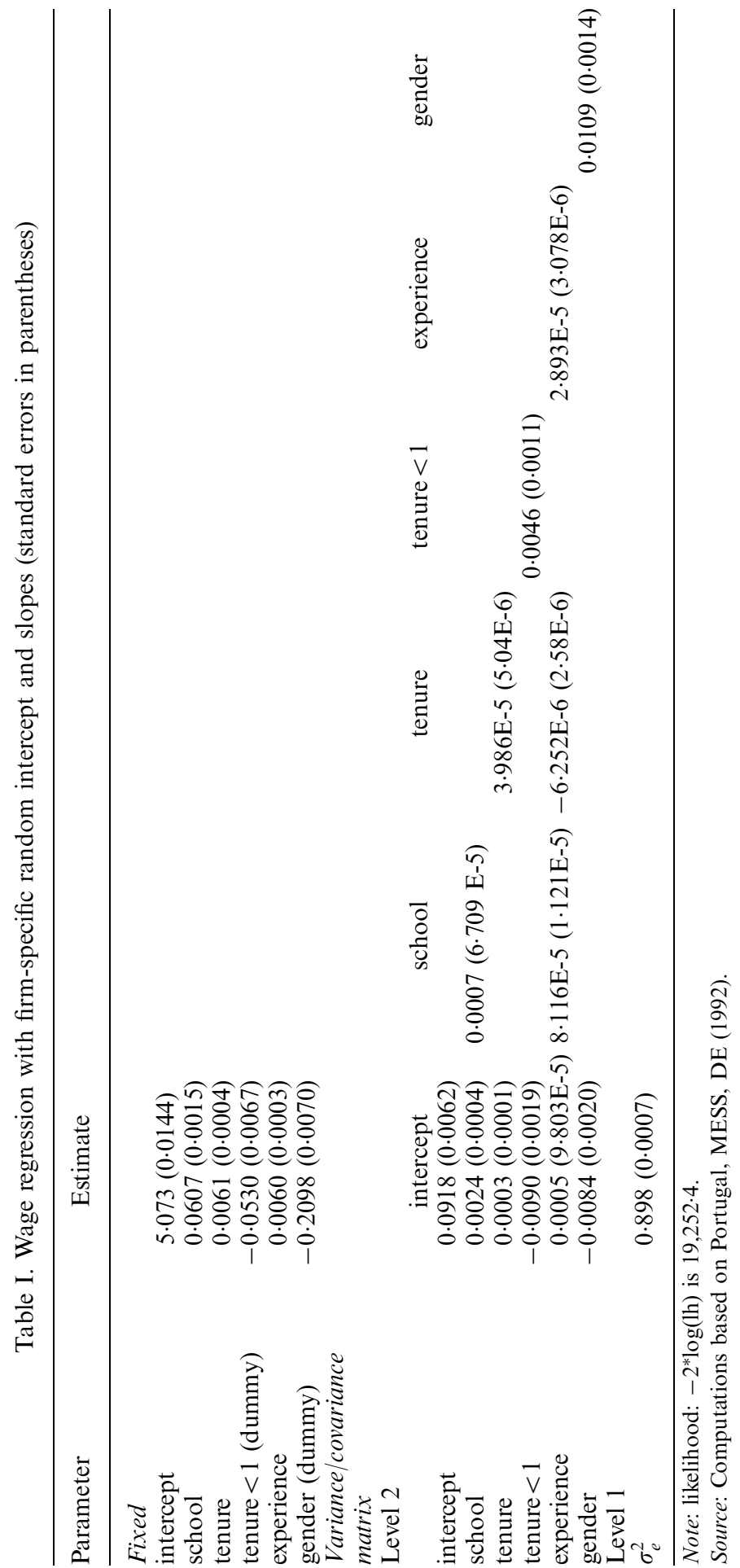


experience is associated with a wage gain of $0.6 \%$. The gender wage gap is captured by the coefficient of -0.21 on the female dummy variable.

Consider now the variation of wage parameters across firms. There is significant variability across firms in the way they reward the attributes of their workers - schooling, tenure, labour market experience, as well as the penalty imposed on women and newcomers to the firm - as proved by the significance of the level- 2 variance of each of the slopes. The wage slopes can therefore by no means be considered as a economy-wide standard, since employers do not follow a universal market rule to reward the characteristics of their workers. Instead, differences in pay parameters across firms are significant. Testing this model against the specification most often found in the literature, which disregards the variability of the pay parameters across firms, leads to a chi-squared statistic of $2101 \cdot 2$, highlighting that the variation of pay parameters across firms should by no means be disregarded.

\section{MODELLING THE FIRM-SPECIFIC WAGE PARAMETERS}

Let us now turn to the explanation of the pattern of wage differences across firms. Referring to equation (2), the impact of the firm attributes on the way it rewards the characteristics of its workers is captured by the estimated parameters $\hat{\eta}$. This section therefore concentrates on the systematic components of the firm-specific wage effects.

Adopting again a general-to-specific modelling approach, a wide set of firm attributes was included in the initial regression to undertake successive testing. Chi-squared tests were used to check the appropriateness of an employer characteristic to explain all the six parameters in the wage regression, and a variable significant for the explanation of at least one pay parameter was kept in the specification for every other pay parameter. Adopting the same specification enables direct comparison of the impact of an employer attribute across its pay parameters. Regarding the variance and covariance matrix, only the elements tested as significant at the $1 \%$ level, according to the likelihood ratio test, were kept in the specific version of the model reported in Table II.

Further specification tests led to the rejection of the hypothesis of homoscedasticity of the level-1 residuals, in favour of a model where those residuals are a function of the firm size, $z_{j}:{ }^{4}$

$$
y_{i j}=X_{i j}^{\prime} \cdot G_{j} \cdot \eta+X_{i j}^{\prime} \cdot \alpha_{j}+e_{i j}+z_{j} \cdot u_{i j}
$$

The normality assumption is not rejected (the Shapiro-Francia test statistic is 0.87695 , with $z=0.03$ and a significance level of 0.488 , in our sample of 36313 observations). The estimation results are reported below.

The much-discussed impact of the firm size on earnings seems to operate through the returns paid to labour market experience and schooling. Indeed, larger firms value more the human capital acquired by their workers in the educational system and their general labour market experience (note the magnitude and significance of the estimated coefficients in Table II).

\footnotetext{
${ }^{4}$ The likelihood ratio test statistic is $239 \cdot 1$, revealing that the variance for workers in larger firms is significantly higher than for workers in smaller firms.
} 
WAGE DIFFERENTIALS ACROSS FIRMS

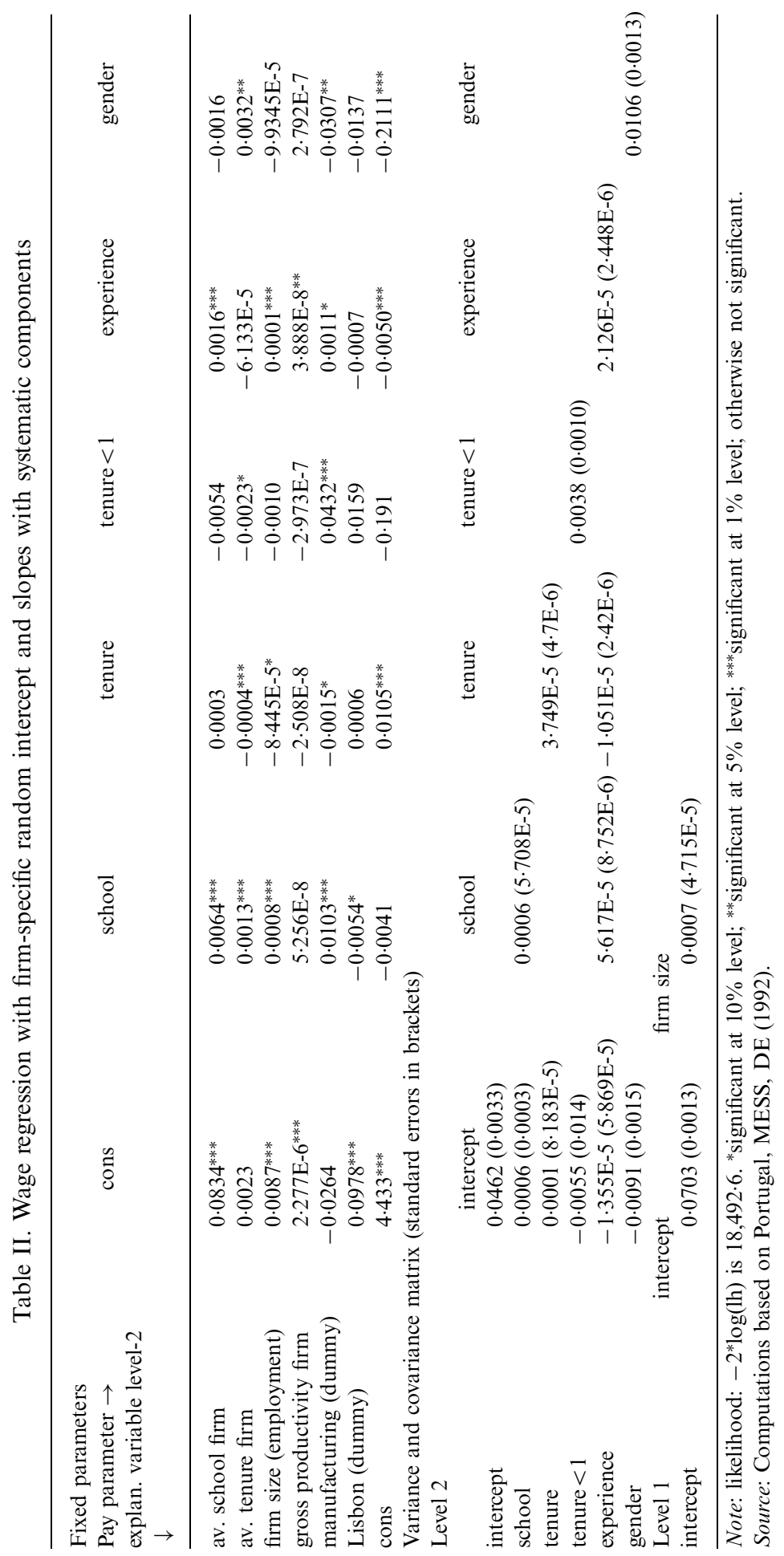

Copyright (C) 2000 John Wiley \& Sons, Ltd.

J. Appl. Econ. 15: 343-354 (2000) 
The gross productivity of the firm (sales volume per employee) can proxy the size of the rents to be divided between workers and employers. According to Currie and McConnell (1992, pp. 300-301), firms with higher sales are more able to pay, have more to loose once a strike happens, and will therefore have a different threat point, being more likely to concede a higher wage. In particular, they reward better the labour market experience of their workforce.

Consider now the impact of the average schooling in the firm. Firms with a better schooled labour force reward better the schooling and labour market experience of their workers. This pattern would be in line with sorting theories, according to which the quality of a worker has an impact on the productivity of his or her co-workers (see, for example, the model by Kremer, 1993). Having schooled co-workers makes everyone more productive, raising the firm's wage level. Another interpretation could highlight that high-paying firms attract better workers. Firms that reward the schooling achievement of the labour force well attract more schooled workers.

Economic sector bounds are relevant in the explanation of each of the firm's pay parameters. In fact, manufacturing rewards the schooling and the experience of the labour force better than services. Also, firms in manufacturing do not impose such a wage disadvantage on their newly hired workers. On the other hand, tenure wage progression is slower in manufacturing, and women earn lower wages than in services. In manufacturing, the split between fringe (newcomers) and core workers is more subtle than in services, as revealed by the lower wage disadvantage imposed on newcomers and the flatter tenure progression scheme. The services sector, instead, is more segmented between newly hired workers and the stable core, whose longer attachment to the firm is rewarded/promoted by higher wages (steeper tenure-wage profile than in manufacturing).

Apart from the variables that were included in the final model, the exclusion of other variables, a-priori expected to be relevant, also deserves a comment. In particular, institutional forces represented by the type of collective bargaining mechanism revealed not to have a significant impact on wages, after other variables had been taken into consideration.

\section{MODELLING THE VARIANCE OF WAGES ACROSS FIRMS}

This section concentrates on modelling the random wage variability across firms. Since random employer-specific slopes are considered, the random term in the model includes an employer component $\left(X_{i j}^{\prime} \cdot \alpha_{j}\right)$, besides the worker component. The wage variance across employers therefore presents a complex structure, being equal to $X_{i j} \cdot \Gamma \cdot X_{i j}^{\prime}$, a quadratic function of the independent variables $X_{i j}$.

Plotting the between-firm wage variance, $X_{i j} \cdot \Gamma \cdot X_{i j}^{\prime}$, against each worker attribute can help explore its pattern. The impact of each variable on the variance at level-2 is evaluated ceteris paribus, holding every other variable constant at its mean value.

Wage dispersion across firms is particularly pronounced for workers with high levels of schooling (see Figure 1). The contrasts among employers when rewarding high levels of schooling may result from the fact that the productive use of a schooling diploma may vary sharply depending on its subject area. Also, the Portuguese educational system has frequently been criticized for providing weak technical preparation, supplying instead workers with a general background, whose productive use may vary sharply across employers. 


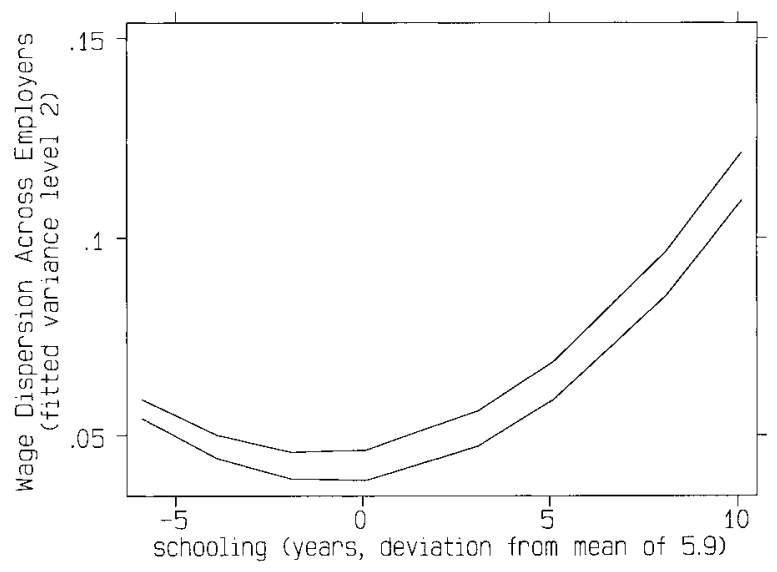

Figure 1. Wage dispersion across employers as a function of schooling. Note: The top line refers to men, and the bottom one to women. Curves for males and females are drawn at the separate male-female means of the variables. Source: Computations based on Portugal, MESS, DE (1992)

Particular aspects of the wage bargaining process in the country can also be highlighted. Indeed, collective bargaining is extensively applied, setting minimum wage levels for different categories of workers. However, wage drift is widespread, as certain firms pay wages above those set by collective bargaining. Note however that wage drift is a selective mechanism, applied mainly to highly skilled and white-collar workers, as revealed by Aperta et al. (1994). The results in Figure 1 are consistent with this framework in the Portuguese labour market, where wage drift helps shape wage contrasts among firms for workers holding higher schooling levels.

Though the same pattern of wage variation across firms holds for the worker tenure, its profile is flatter and it does not reach values as high as those generated by schooling (see Figure 2).

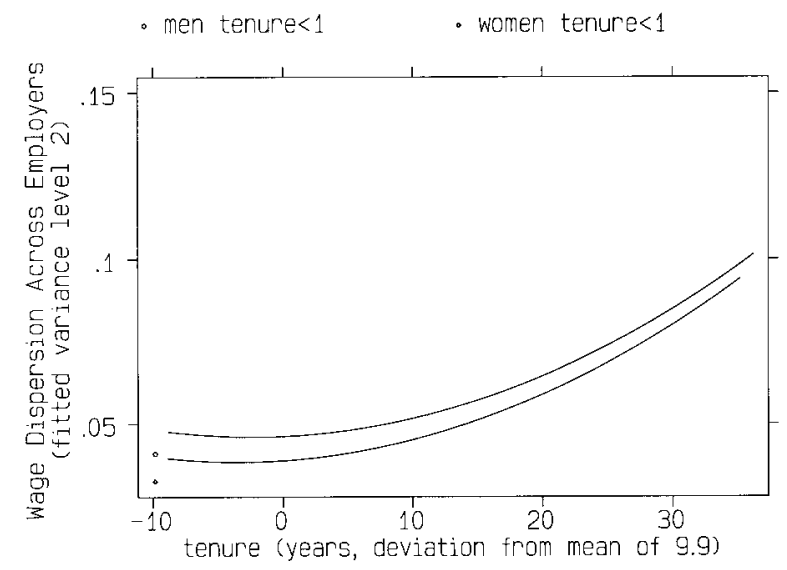

Figure 2. Wage dispersion across employers as a function of tenure. Note: The top line refers to men, and the bottom one to women. Curves for males and females are drawn at the separate male-female means of the variables. Source: Computations based on Portugal, MESS, DE (1992) 


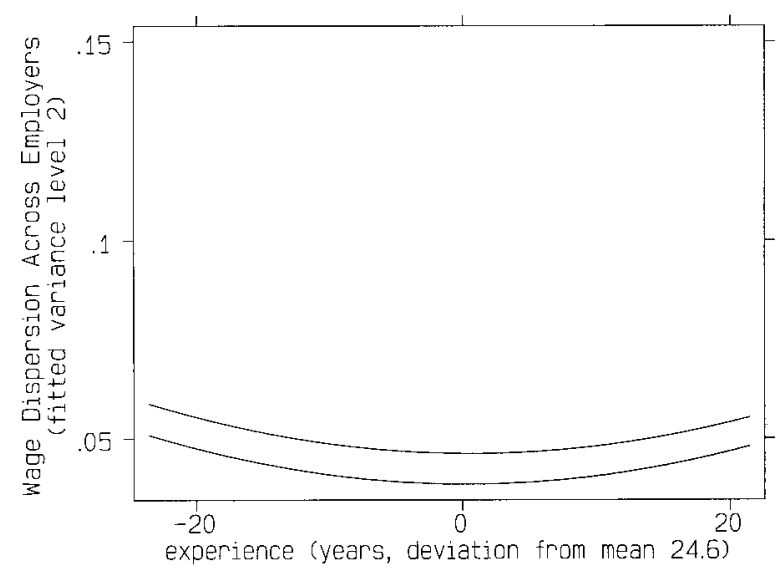

Figure 3. Wage dispersion across employers as a function of experience. Note: The top line refers to men, and the bottom one to women. Curves for males and females are drawn at the separate male-female means of the variables. Source: Computations based on Portugal, MESS, DE (1992)

Different firms therefore seem to attach different relevance to the specific human capital acquired within the company. For the firms that encourage long-term employment relationships by rewarding tenure, turnover efficiency wage theories could apply, if for example training costs were high and turnover were thus costly to the firm.

The productive usefulness of human capital acquired on the market place (experience) is valued in a more uniform way by employers than the benefits of schooling or tenure. In fact, the returns of experience present a low dispersion across firms, when compared to the returns to the other worker attributes (Figure 3).

\section{CONCLUSIONS}

Multilevel modelling allows a concise treatment of the following issues: differences in pay policies across firms; modelling the firm-specific parameters of the pay policy; modelling the wage variance across employers.

Results reveal that differences across employers' pay policies are significant. Moreover, they concern every parameter of the pay policy. The returns to schooling, tenure, labour market experience, as well as the penalty imposed on women and newly-hired workers present significant variability across firms. Therefore, contrasts among company wage policies can only partially be captured by a procedure which assumes that firms follow a market rule to reward observable human capital, imposing a uniform wage advantage/disadvantage on all of their labour force.

Wage divergence across firms rises particularly sharply with the schooling of the workers, reflecting the existence of a certain consensus regarding the productive usefulness of low and average schooling levels in the economy, but widely diverging judgements on the productive advantages of higher levels of schooling. The productive use of a school diploma may vary sharply, depending on its subject area. This can also be linked to a criticism often heard about the educational system in Portugal, which focuses on its too general nature and its inability to provide specific skills directly usable in the productive process. While some employers may value 
the ability to learn that high educational levels may provide, others instead seem to consider the productive skills of workers with high schooling levels rather low.

There is a particular logic binding together the pay policies of different firms, as systematic components can be identified in the firm-specific wage parameters. In particular, firms with a more schooled labour force, larger ones, those where gross labour productivity is higher and those in manufacturing reward their workforce better, through higher returns to schooling and experience.

\section{APPENDIX: DESCRIPTIVE STATISTICS}

Worker Attributes, 1992

\begin{tabular}{lrr}
\hline Variable & & $\%$ \\
\hline Schooling (years) & $<=4$ & $56 \cdot 7$ \\
& 6 & $18 \cdot 6$ \\
& $9 \cdot 6$ \\
& 11 & $12 \cdot 9$ \\
& 14 & 1.3 \\
Average tenure & 16 & $1 \cdot 9$ \\
Share of workers with tenure $<=1$ year (\%) & & $9 \cdot 9$ \\
Average (potential) experience & & $14 \cdot 3$ \\
Share of females (\%) & & $24 \cdot 6$ \\
Number of workers & & $36 \cdot 4$ \\
& & 36313 \\
\hline
\end{tabular}

Firm Attributes, 1992

\begin{tabular}{llr}
\hline Variable & & $\%$ \\
\hline Industry & manufacturing & $60 \cdot 9$ \\
& construction & $5 \cdot 6$ \\
Region & services & $33 \cdot 5$ \\
& Lisbon and Tagus Valley & $40 \cdot 0$ \\
Average firm size & Coastal North & $32 \cdot 8$ \\
Number of firms & other & $27 \cdot 2$ \\
& & $91 \cdot 5$ \\
\hline
\end{tabular}

\section{ACKNOWLEDGEMENTS}

I am grateful to John Micklewright for constructive comments and Pravin Trivedi for advice on the choice of the econometric model. Comments by Robert Waldmann, Stephen Nickell, Stephen Machin and three anonymous referees led to improvements on an earlier version of the paper. The European University Institute, Florence, Italy, provided institutional support while I was working on my PhD on which this paper is based. Financial support was provided by the Ministério dos Negócios Estrangeiros, Portugal. 


\section{REFERENCES}

Abowd JM, Kramarz F, Margolis DN. 1999. High-wage workers and high-wage firms. Econometrica. 67: 251-333.

Aperta A, Moreira I, Murteira MM. 1994. Análise das Diferenciações Entre Remunerações Convencionais e Efectivas. Coleç̧ão Estudos, Série Rendimentos, 7. MESS (Ministério do Emprego e da Segurança Social): Lisbon.

Currie J, McConnell S. 1992. Firm-specific determinants of the real wage. Review of Economics and Statistics 74: $297-304$.

Dunlop JT. 1957. The task of contemporary wage theory. In The Theory of Wage Determination, Dunlop JT (ed.). Macmillan: London; 3-27.

Goldstein H. 1986. Multilevel mixed linear model analysis using iterative generalized least squares. Biometrika 73: 43-56.

Goldstein H. 1995. Multilevel Statistical Models. Edward Arnold: London.

Gould W, Rogers W. 1991. Summary of tests of normality. Stata technical bulletin 3. Stata Press: College Station, TX, 20-23.

Groshen EL. 1991. Sources of intra-industry wage dispersion: how much do employers matter? Quarterly Journal of Economics 106: 869-884.

Haitovsky Y. 1986. The linear hierarchical model and its applications in economic analysis. In Bayesian Inference and Decision Techniques - Essays in Honor of Bruno de Finetti, Goel PM, Zellner A (eds). Elsevier: Amsterdam; 119-138.

Kerr C. 1994. The social economics revisionists: the 'real world' of labor markets and institutions. In Labor Economics and Industrial Relations: Markets and Institutions, Kerr C, Staudohar PD (eds). Harvard University Press: Cambridge, MA; 66-108.

Knight JB, Sabot RH. 1983. The role of the firm in wage determination: an African case study. Oxford Economic Papers 35: 45-66.

Kramarz F, Lollivier S, Pele LP. 1996. Wage inequalities and firm-specific compensation policies in France. Annales d'Economie et de Statistique 41/42: 369-386.

Kremer M. 1993. The O-ring theory of economic development. Quarterly Journal of Economics 108: 551575.

Leonard JS. 1989. Wage structure and dynamics in the electronics industry. Industrial Relations 28: $251-275$.

Lester RA. 1948. Company Wage Policies: A Survey of Patterns and Experience. Princeton University Press: Princeton, NJ.

Lester RA. 1952. A range theory of wage differentials. Industrial and Labor Relations Review 5: $483-500$.

Lindley DV, Smith AFM. 1972. Bayes estimates for the linear model. Journal of the Royal Statistical Society, Series B 34: 1-18.

Longford NT. 1993. Random Coefficient Models. Oxford University Press: Oxford.

Lucifora C. 1993. Market structure, financial performance and wage determination: an empirical analysis for medium-large manufacturing firms in Italy. Economic Notes by Monte dei Paschi di Siena 22: 80-104.

Modesto L, Monteiro ML. 1993. Wages, productivity and efficiency: an empirical study for the Portuguese manufacturing sector. Economia 17: 1-25.

OECD (Organization for Economic Co-operation and Development). 1992. OECD Economic Surveys, Portugal, 1991/92. OECD: Paris.

Ministério do Emprego e da Segurança Social. 1992. Quadros de Pessoal, Data in magnetic medium. Departamento de Estatística, Ministério do Emprego e da Segurança Social: Portugal.

Rees A, Shultz GP. 1970. Workers and Wages in an Urban Labor Market. University of Chicago Press: Chicago, IL.

Reynolds LG. 1951. The Structure of Labor Markets. Greenwood Press: Westport, CT.

Vieira JAC, Hartog J, Pereira PT. 1997. A look at changes in the Portuguese wage structure and job level allocation during the 1980s and early 1990s, Tinbergen Institute discussion paper TI 97-008/3. TI: Amsterdam.

Woodhouse G, Rasbash J, Goldstein H, Yang M. 1996. Introduction to multilevel modelling. In Multilevel Modelling Applications: a Guide for Users of MLn, Woodhouse G (ed.). Institute of Education, University of London: London; 9-57. 